\section{Ribonuclease L (RNase L)}

Melissa Drappier and Thomas Michiels de Duve Institute, Université catholique de Louvain, Brussels, Belgium

\section{Synonyms}

PRCA1; RNS4

\section{Historical Background}

In early stages of viral infection, the innate immune response and particularly the interferon response play a critical role in restricting viral replication and propagation, awaiting the establishment of the adaptive immune response. One of the best-described IFN-dependent antiviral responses is the OAS/RNase L pathway. This two-component system is controlled by type I and type III interferons (IFN). Back in the 1970 s, the groups of I. Kerr and P. Lengyel discovered a cellular endoribonuclease (RNase) activity that was increased by IFN and depended on the presence of double-stranded RNA (dsRNA) (Brown et al. 1976; Kerr et al. 1977). Further, a correlation was found between this RNase activity and the synthesis of unusual $2^{\prime}-5^{\prime}$ oligoadenylates (2-5A) (Fig. 1) by a family of enzymes called oligoadenylate synthetases
(OAS) [(Baglioni et al. 1978), reviewed by (Hovanessian and Justesen 2007)].

Based on these observations, an RNase L activation model was proposed (Fig. 2). In this model, virus infection induces IFN expression, which, in turn, triggers the upregulation of OAS expression. dsRNA synthesized in the course of viral infection binds OAS, leading to the activation of OAS catalytic activity and to the synthesis of 2-5A molecules. 2-5A in turn bind to RNase L, which is present in cells as a latent enzyme. Upon 2-5A binding, RNase $\mathrm{L}$ becomes activated by dimerization and cleaves viral and cellular RNA (Fig. 2).

Since then, cloning of the RNase L gene in 1993 (Zhou et al. 1993), generation of RNase L-deficient (RNase $\mathrm{L}^{-1-}$ ) mice in 1997 (Zhou et al. 1997), and solving RNase L structure (Han et al. 2014; Huang et al. 2014) were the major milestones in the understanding of RNase L function.

\section{General Features, Biochemistry, and Regulation of RNase L Activity}

RNase $L$ is the effector enzyme of the IFN-induced, OAS/RNase L pathway. The gene encoding $\mathrm{RNase} \mathrm{L}$ is present in higher vertebrates (birds, reptiles, and mammals) but not in insects or fish. RNase L is constitutively expressed at low levels in most cell types. Its activation however depends on 2-5A synthesized by OAS, whose 


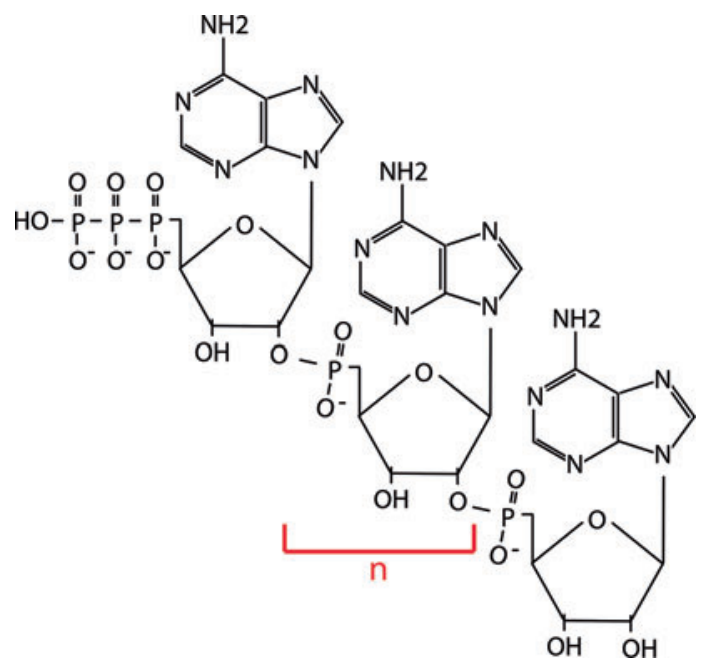

Ribonuclease L (RNase L), Fig. 1 Structure of $2^{\prime}-5^{\prime}$ oligoadenylates (2-5A). 2-5A are short oligoadenylates linked by $2^{\prime}, 5^{\prime}$-phosphodiester bonds. They contain one to three phosphate groups at their $5^{\prime}$ end and at least
3 adenylyl residues $(\mathrm{n} \geq 1)$. Naturally occurring $2-5 \mathrm{~A}$ molecules contain three phosphate groups at their $5^{\prime}$ end, but a single phosphate is sufficient for RNase $\mathrm{L}$ activation

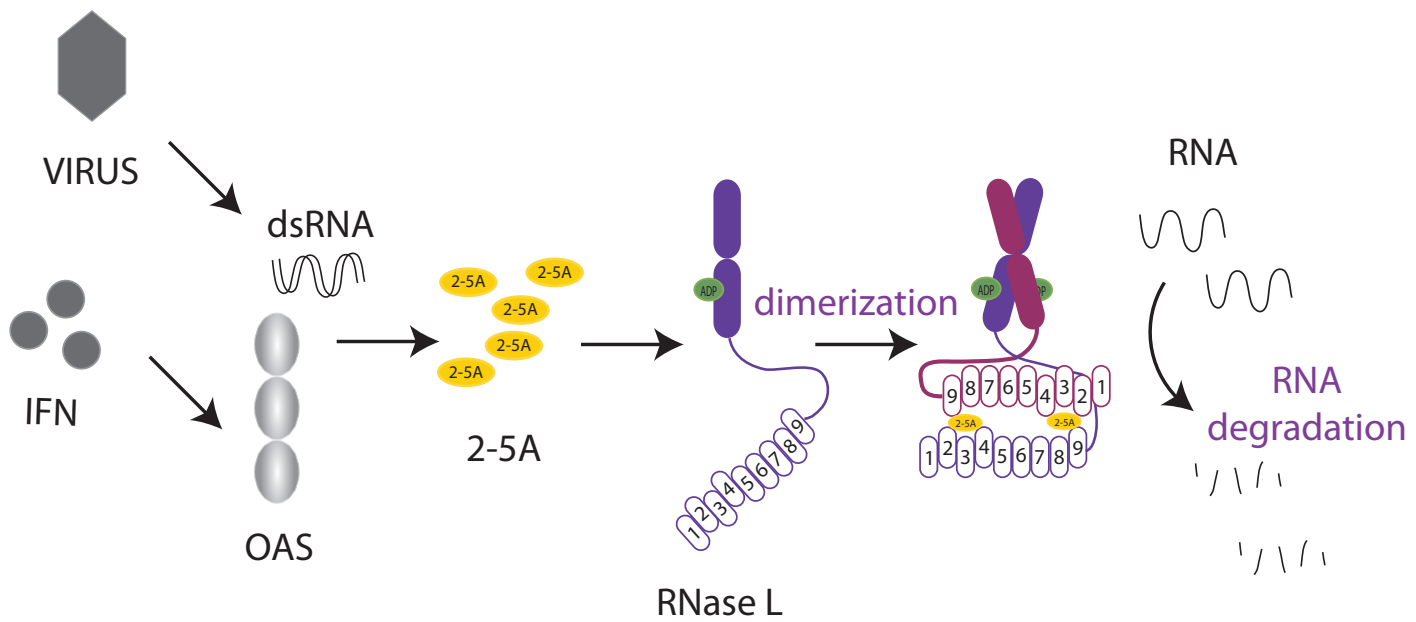

Ribonuclease L (RNase L), Fig. 2 RNase L activation pathway. In response to IFN- $\alpha / \beta$ or IFN- $\lambda$, OAS gene transcription is upregulated. OAS are produced as inactive enzymes but become activated in the presence of dsRNA (i.e., after viral infection). OAS then synthetize 2-5A, which bind to ankyrin repeats of RNase $\mathrm{L}$ and trigger RNase $\mathrm{L}$ dimerization and activation. Active RNase $\mathrm{L}$ degrades viral and cellular RNA basal expression is low but IFN inducible in most cell types except for dendritic cells and macrophages where basal OAS levels are higher. RNase $\mathrm{L}$ is typically described as a cytosolic enzyme, but it was also detected in other subcellular compartments such as the nucleus and mitochondria
[(Le Roy et al. 2007), reviewed by (Ezelle et al. 2016)].

RNase L is a 741-amino-acid-long endoribonuclease $(83,5 \mathrm{kDa})$ formed of three conserved domains (Fig. 3): 


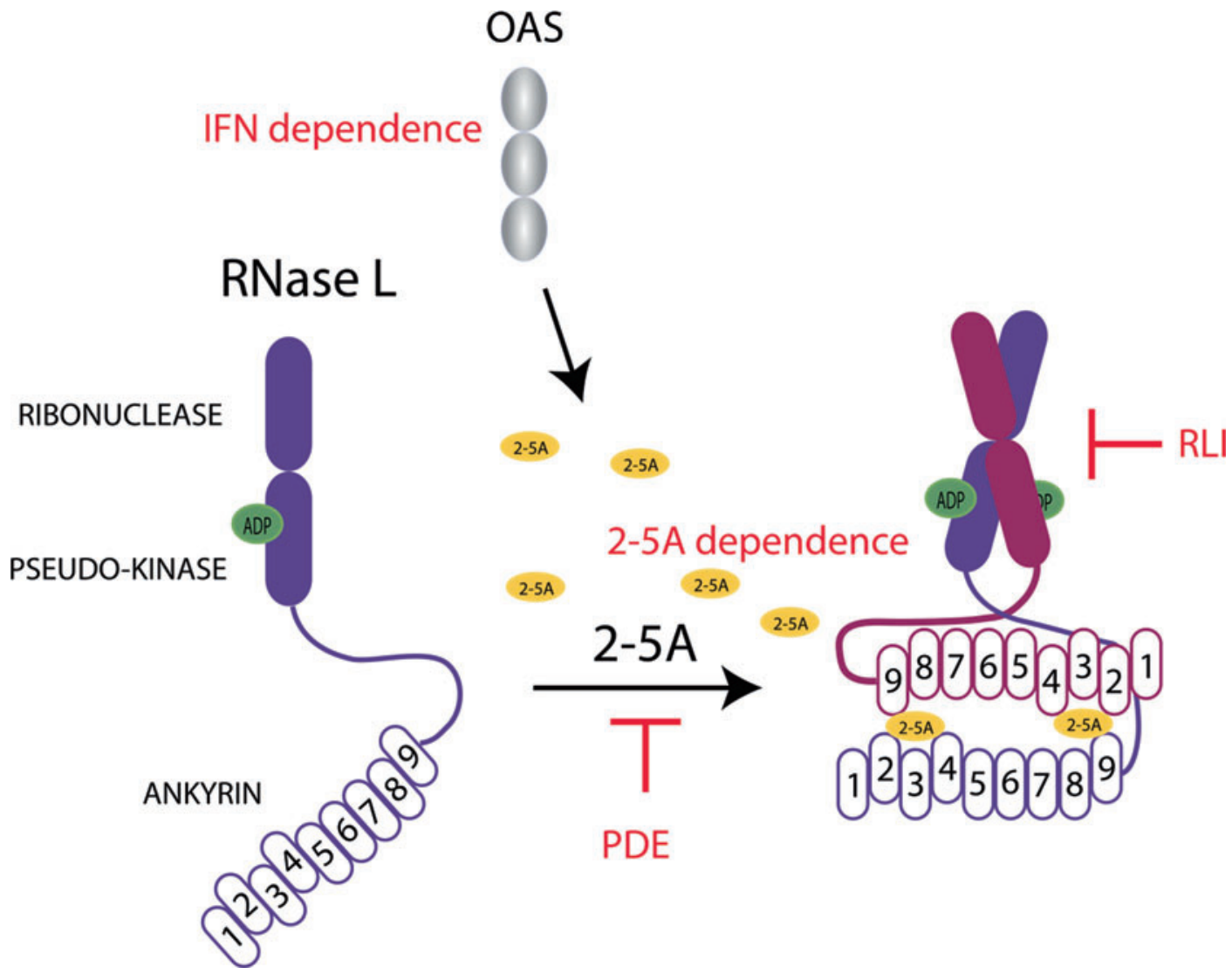

Ribonuclease L (RNase L), Fig. 3 RNase L activation and control. RNase L is composed of three domains: the $\mathrm{N}$-terminal ankyrin domain; the central pseudokinase domain, which binds nucleotides; and the C-terminal endoribonuclease domain. 2-5A bind ankyrin repeats $\mathrm{R} 2$ and $\mathrm{R} 4$ of one RNase L protomer and R9 and the pseudokinase $\mathrm{N}$-terminal lobe of the other protomer. ATP/ADP binding

(1) The N-terminal ankyrin domain is composed of nine ankyrin repeats (R1-R9) and acts as the sensor and regulatory domain of the enzyme. It binds 2-5A, which trigger RNase $\mathrm{L}$ dimerization and activation. Ankyrin repeats are 33-residue motifs consisting of two $\alpha$-helices separated by loops, which usually mediate protein-protein interactions. In absence of 2-5A, the ANK domain maintains RNase $\mathrm{L}$ in a monomeric inactive state.

(2) The central protein kinase-like or pseudokinase domain exhibits significant similarity to protein kinases, markedly to Ire1, an ER transmembrane sensor implicated in the to the pseudokinase domain contributes to RNase $\mathrm{L}$ dimerization. Tight control of RNase $\mathrm{L}$ activation includes gene transcription dependence on IFN, OAS activity dependence on dsRNA, rapid degradation of 2$5 \mathrm{~A}$ by $2^{\prime}$ phosphodiesterases (PDE), and inhibition of RNase $\mathrm{L}$ by the cellular protein RLI

unfolded protein response (Lee et al. 2008). Despite this similarity, the pseudokinase domain is catalytically inactive due to the lack of several residues critical for catalytic kinase activity (Dong and Silverman 1999). This central domain however binds ADP or ATP and plays a role in RNase $\mathrm{L}$ dimerization.

(3) The C-terminal domain is the endoribonuclease enzymatic domain, responsible for target RNA cleavage. It cleaves cellular and viral RNA with little specificity. It predominantly cleaves after UU or UA dinucleotides and, more broadly, recognizes the $\mathrm{UN}^{\wedge} \mathrm{N}$ pattern, promoting cleavage $3^{\prime}$ of $\mathrm{UN}$ 
sequence, leaving a $5^{\prime}-\mathrm{OH}$ end and $3^{\prime}-2^{\prime}$ cyclic phosphoryl group.

(4) Recent structural studies show that 2-5A bind $\mathrm{R} 2$ and R4 of one RNase L protomer and R9 and the pseudokinase N-terminal lobe of the other protomer (Han et al. 2012, 2014; Huang et al. 2014). Thus, 2-5A promotes RNase $\mathrm{L}$ self-association by acting as a template that fills the interface between two copies of the ANK domain (Fig. 3).

Though some control of its expression exists at the posttranscriptional level, RNase L is constitutively expressed as a latent enzyme. Its activity needs to be tightly regulated since uncontrolled RNase L activity would lead to cellular RNA degradation and apoptosis. Several layers of RNase L activity control exist:

(1) Activation of the pathway can be mediated by type I (IFN- $\alpha / \beta)$ and type III (IFN- $\lambda$ ) interferons (IFN), which are generally produced upon viral infection of a tissue. IFNs trigger the upregulation of $O A S$ gene transcription.

(2) OAS catalytic activity itself depends on the presence of cytoplasmic dsRNA, which is typically produced when a virus replicates in the cell. From ATP, activated OAS catalyze the synthesis of 2-5A, which are very potent RNase $\mathrm{L}$ activators effective at subnanomolar concentrations.

(3) 2-5A are degraded within minutes of their synthesis, by $2^{\prime}$-phosphodiesterases (PDE) and phosphatases. The presence of intracellular 2-5A is thus transient and directly mirrors OAS activity.

(4) RNase L was reported to undergo posttranslational modifications like ubiquitylation and hydroxylation, which can affect function and stability.

(5) RNase L activity can also be negatively regulated by the RNase L inhibitor (RLI), a cellular factor also known as inhibitor-/ATPbinding cassette, subfamily $\mathrm{E}$ member 1 (ABCE1) (Martinand et al. 1998).

\section{Cellular Functions of RNase $\mathbf{L}$}

Although RNase L knockout mice are viable and display no overt phenotype, it has become clear that RNase $\mathrm{L}$ activity is required for fine-tuning of important cellular processes, including cell proliferation and differentiation, apoptosis, or maintenance of cytoskeleton integrity. In human, associations have been found between RNase $\mathrm{L}$ activity and susceptibility to cancer or chronic fatigue syndrome (Fig. 4) [see reviews by (Bisbal and Silverman 2007; Ezelle et al. 2016; Gusho et al. 2016)].

(1) Regulation of mRNA translation and stability: The major effects of RNase L on cellular processes depend on its nuclease activity, whereby RNase L regulates mRNA turnover. Recent transcriptomic studies suggest that RNase L exhibits some specificity toward some mRNA targets. It was proposed that proteins interacting with RNase $\mathrm{L}$ might direct the nuclease toward specific cell compartments or toward a subset of mRNA. For instance, RNase L regulates mRNA translation through its association with the translation termination factor eRF3 (Le Roy et al. 2005). It can increase both translation read-through at premature termination codons and +1 frameshift efficiency, the latter mechanism being, for instance, involved in the expression of ornithine decarboxylase antizyme 1 (OAZ1). eRF3 is thought to address $\mathrm{RNase} \mathrm{L}$ to polysomes. RNase L also interacts with tristetraprolin (TTP), a protein known to interact with AU-rich sequences found in the $3^{\prime}$ noncoding regions of short-lived mRNA. TTP may thus guide RNase L to mRNA carrying AU-rich sequences (Brennan-Laun et al. 2014). A mitochondrial translation initiation factor called IF2mt was identified in a two-hybrid screen as another RNase $\mathrm{L}$ interactor. This factor would promote RNase $\mathrm{L}$ access to the mitochondria where RNase L was shown to degrade mtRNA (Le Roy et al. 2007). 


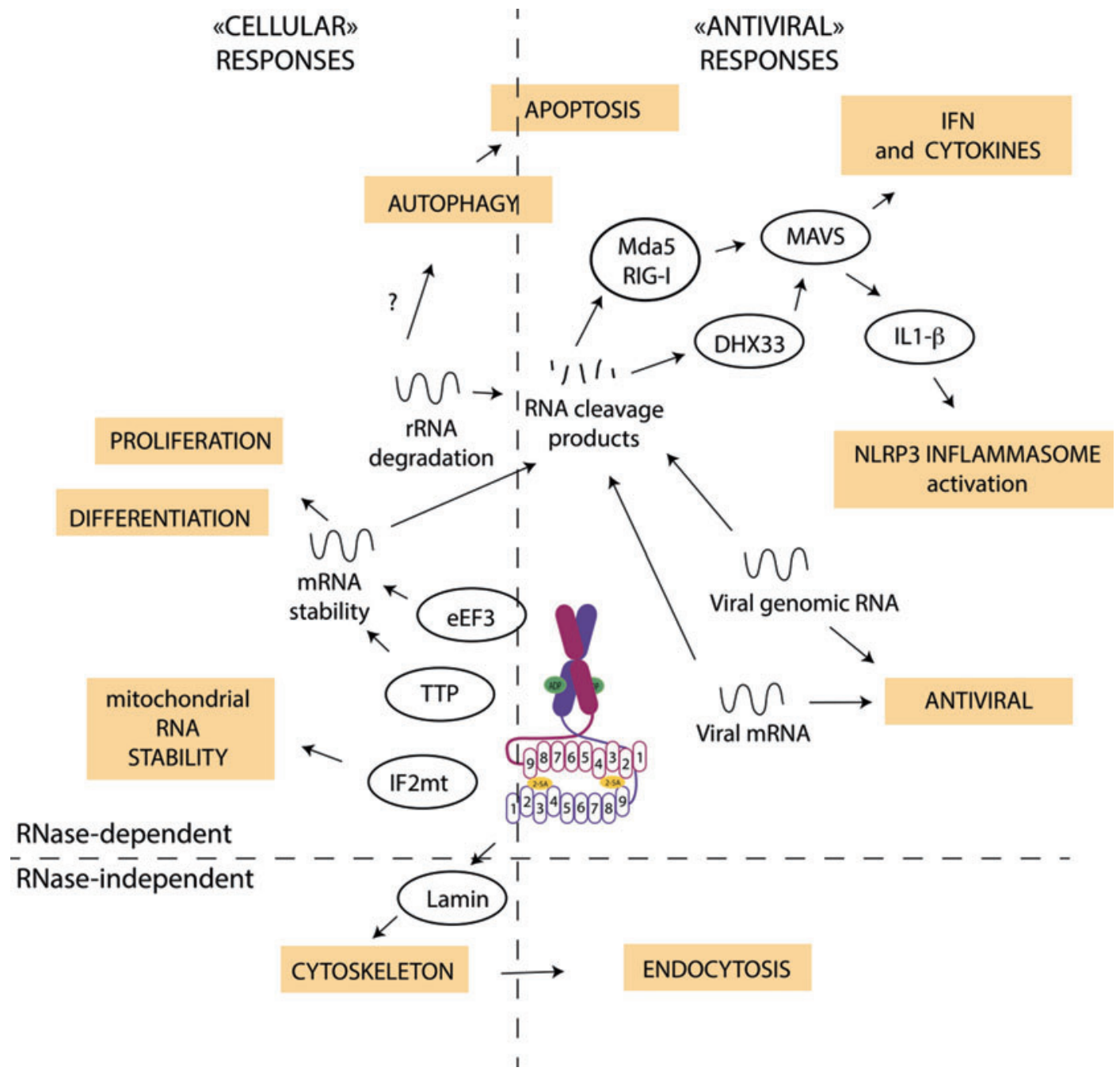

Ribonuclease L (RNase L), Fig. 4 Cellular and antiviral functions of RNase L

By regulating the turnover of several mRNA, RNase L was shown to regulate important processes such as muscle cell differentiation and cell cycle progression. Accordingly, evidence of a tumor suppressor function of RNase L has emerged from studies on the genetics of hereditary prostate cancer. Indeed, several germline mutations or variants were observed among families with high risk of prostate cancer. Likewise, RNase L polymorphisms were suggested to be associated with various cancer types such as pancreatic, head and neck, uterine cervix, and breast cancer.
(2) Apoptosis and autophagy: RNase L has been implicated in the induction of autophagy in response to viral infection. The mechanism of autophagy induction was not fully elucidated but likely stems from ribosomal RNA degradation. The process was reported to involve the IFN-dependent protein kinase R (PKR) and c-Jun kinase activation. Interestingly, sustained RNase L-mediated degradation of cellular RNA, including that of mitochondrial RNA, leads to apoptosis. RNase L cleavage products were shown to participate in the transition from autophagy to apoptosis through caspase 3 activation, which promotes 
cleavage of Beclin-1 and cytochrome C release (Chakrabarti et al. 2012; Siddiqui and Malathi 2012).

(3) Cytoskeleton remodeling: Under its inactive, non-2-5A bond conformation, RNase L can bind several cytoskeletal proteins, including $\beta$-actin and $\beta$-actin partners such as filamin A, which acts as a scaffold to associate yet other partners to the cytoskeleton. Interestingly, this RNase L function is independent of ribonuclease catalytic activity. By binding to cytoskeletal proteins, RNase L was suggested to be involved in the maintenance of epithelial barrier integrity [reviewed in depth in (Ezelle et al. 2016)].

\section{Immune Response Modulation}

The various RNase $\mathrm{L}$ activities mentioned above not only control cell physiology but also contribute to modulate immune responses to viruses or bacteria (Fig. 4). mRNA encoding PKR and various IFN effectors were shown to be targeted by RNase L; Autophagy and apoptosis are wellknown antiviral cell responses that contribute to slow down virus replication and to initiate adaptive responses; Action of RNase L on the cytoskeleton was reported to negatively regulate endocytosis, thereby decreasing viral infection efficiency. Also, the cytoskeleton interacts with many innate immunity components to regulate their activation.

Additional immunomodulatory activities are thought to depend on the generation, by RNase L, of short RNA products carrying a $3^{\prime}-2^{\prime}$ cyclic phosphate, which act as pathogenassociated molecular patterns (PAMPs) and thereby activate innate immune responses (Fig. 4) [see (Ezelle et al. 2016; Gusho et al. 2016)].

(1) RNA cleavage products shorter than $200 \mathrm{bp}$ were shown to activate RIG-like helicases (Mda5 and/or RIG-I), which act through the adapter MAVS to induce IFN production. This pathway thus provides an amplification loop in the initiation of the IFN response (Malathi et al. 2007).

(2) RNase L was recently shown to trigger the activation of the NLRP3 inflammasome by increasing IL-1 $\beta$ production (Chakrabarti et al. 2015). Again, this activation appears to be mediated by RNA cleavage products that act through a pathway involving the cytosolic helicase DHX33 and MAVS.

(3) As indicated above, RNA cleavage products are also responsible for the transition between autophagy and apoptosis.

(4) Besides, RNase L action was reported to contribute to antibacterial immunity, namely, against Bacillus anthracis and enteropathogenic Escherichia coli. RNase L activity correlates with decreased levels of LAMP1/ LAMP2 factors that are involved in phagocyte maturation.

\section{Antiviral Activities of RNase $L$ and Viral Evasion Strategies}

Numerous viruses, mostly RNA viruses, were shown to be susceptible to RNase L activity because they replicated better in RNase L-deficient mice or in RNA-deficient cells than in wild-type controls. The influence of RNase $\mathrm{L}$ against DNA viruses and retroviruses was also reported. Antiviral activity of RNase L results from both direct and indirect consequences of RNA cleavage (Fig. 4) [reviewed in (Drappier and Michiels 2015)].

(1) Activated RNase L may directly cleave the genome of RNA viruses. It may also trigger the degradation of viral mRNA produced by both DNA and RNA viruses and thereby inhibit viral protein synthesis and replication. Interestingly, it was proposed that OAS activation might preferentially occur in the vicinity of viral replication complexes, where dsRNA is produced, thereby imparting some specificity to the degradation of viral mRNA that is located close to replication complexes.

(2) Damage to host cell machinery through rRNA and mRNA degradation can affect many 
cellular processes and notably translation, including that of viral mRNA, thereby impairing viral replication. Besides, significant degradation of cellular RNA leads to apoptosis, which results in the elimination of virus-infected cells.

Many viruses, including DNA viruses, were however shown to counteract the OAS/RNase $\mathrm{L}$ pathway, which is a strong argument in favor of the importance of RNase L in antiviral activity. Each step of the signaling pathway can be targeted (Fig. 5) [reviewed in (Drappier and Michiels 2015)]:

Some viruses act upstream of the pathway by masking or limiting accumulation of dsRNA. For example, Vaccinia virus (VV) is known to produce protein E3L, which sequesters dsRNA and thereby prevents OAS activation as well activation of other antiviral pathways that are activated by dsRNA. Recently, VV was also shown to hijack the cellular exoribonuclease Xrn1 to contribute to degrade RNA products that otherwise would activate the OAS/RNase L pathway (Burgess and Mohr 2015; Liu et al. 2015). DNA viruses were also reported to trigger the production of inactive 2-5A and related inhibitory compounds.

Some viruses more directly target RNase $\mathrm{L}$ activity. Examples are human immunodeficiency virus (HIV) or Encephalomyocarditis virus (EMCV) that induce the expression of the cellular RNase L inhibitor, RLI (ABCE) (Martinand et al. 1998). More recently, it was shown that several viruses, including Middle East respiratory syndrome coronavirus (MERS) were producing $2^{\prime} 5^{\prime}$ phosphodiesterases (PDE), which quickly degrade 2-5A and thus prevent RNase $\mathrm{L}$ activation (Zhao et al. 2012; Thornbrough et al. 2016).

Up to now, a single virus, Theiler's murine encephalomyelitis virus (TMEV or Theiler's virus), was shown to produce a protein that binds and inhibits RNase $\mathrm{L}$ through direct protein-protein interaction (Sorgeloos et al. 2013).

Other strategies to evade RNase L cleavages are due to the structures and sequence of viral RNA genomes: Poliovirus genomic RNA contains a highly structured hairpin that acts as a cleavage-resistant substrate of RNase L (Townsend et al. 2008). Hepatitis C virus (HCV) RNA has evolved as to decrease the number of UA and UU dinucleotides that are targeted by RNase L.

The number of viral proteins that are discovered to inhibit the OAS/RNase L pathway increases rapidly. This underlines the overall impact of RNase L on viral infection and may explain why some viruses did not replicate to significantly higher levels in RNase L KO than in wild-type mice.

\section{Summary}

The OAS/RNase L pathway is one of the bestcharacterized IFN effector pathways. It was initially discovered as an antiviral pathway, but increasing evidences suggest that it also acts to fine-tune some physiological processes such as cell proliferation and differentiation. Yet, the most important role of RNase L is likely its antiviral activity. Viruses developed many strategies to evade the activity of the OAS/RNase $\mathrm{L}$ pathway, thereby underlining the efficiency of RNase L antiviral action. Some of these viruses are known to infect macrophages or dendritic cells where the RNase L pathway does not need priming by IFN, as OAS levels are constitutively higher than in other cells.

Given its ability to degrade cellular RNA and to trigger apoptosis, RNase L activity must be tightly controlled. More and more attention is brought to IFN-inducible enzymes such as the RNA-editing enzyme ADAR1 or the deoxynucleotide triphosphohydrolase SAMHD1, which act, as RNase L, to control the levels of unconventional nucleic acids in the cell. On one hand, they have antiviral functions and contribute to enhance the IFN response upon infection. On the other hand, in the absence of infection, they 

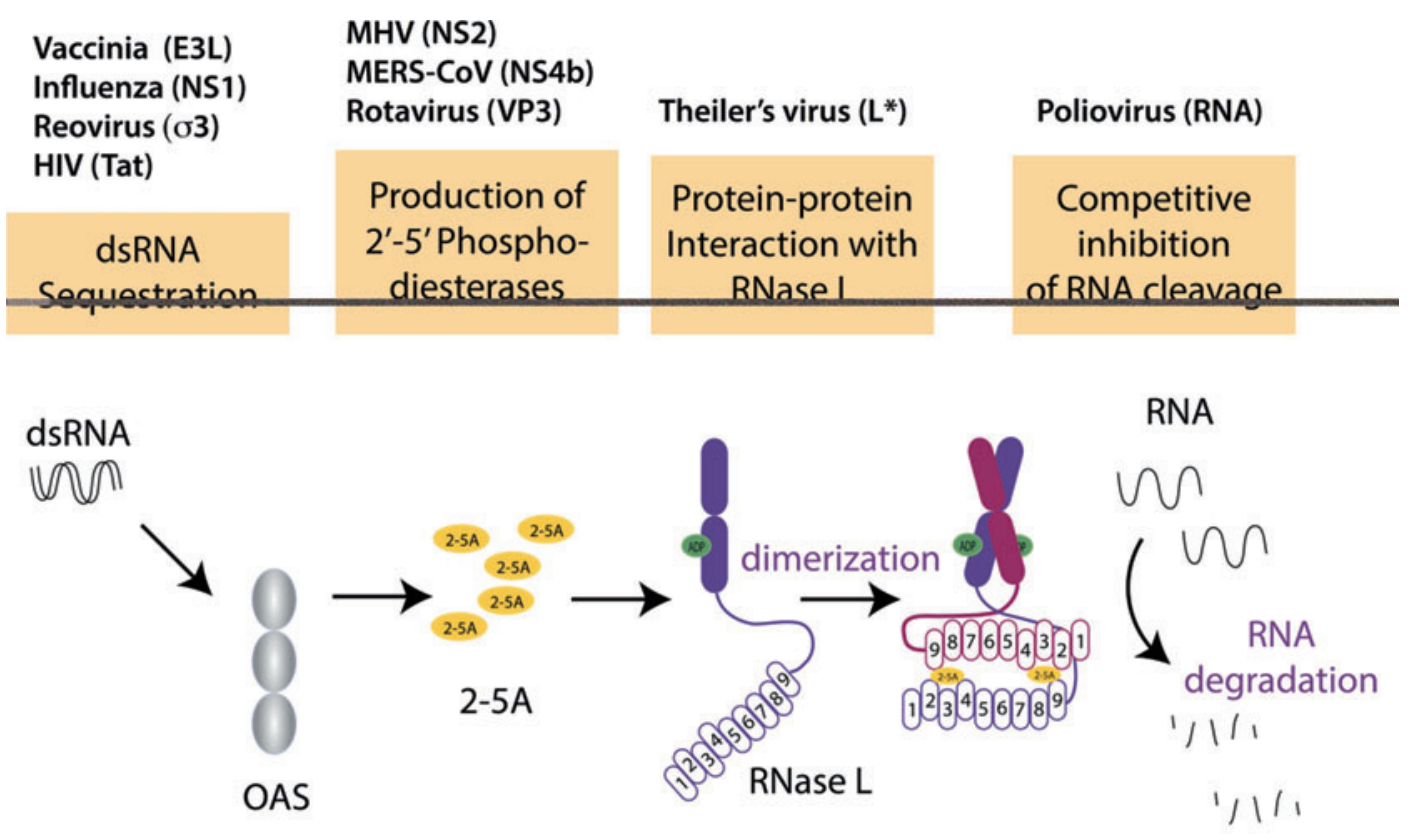

\begin{tabular}{c|l|c|c|}
$\begin{array}{c}\text { Viral RNA decapping } \\
\text { and degradation by } \\
\text { exonuclease Xrn1 }\end{array}$ & $\begin{array}{l}\text { Production of } \\
\text { inactive 2-5A }\end{array}$ & $\begin{array}{c}\text { RLI } \\
\text { upregulation }\end{array}$ & $\begin{array}{c}\text { Viral genome } \\
\text { with fewer } \\
\text { cleavage sites }\end{array}$ \\
\hline Vaccinia & $\begin{array}{l}\text { Vaccinia } \\
\text { SV40 } \\
\text { Herpes simplex }\end{array}$ & $\begin{array}{l}\text { EMCV } \\
\text { HIV }\end{array}$ & HCV \\
\hline
\end{tabular}

Ribonuclease L (RNase L), Fig. 5 Inhibition of the OAS/RNase L pathway by viruses

act to lower endogenous retro-element activity to prevent uncontrolled activation of sensors such as RIG-like helicases and consequent IFN production. Unbalanced regulation of these enzymes can result in diseases like cancer or interferonopathies.

\section{References}

Baglioni C, Minks MA, Maroney PA. Interferon action may be mediated by activation of a nuclease by pppA2' $5^{\prime} \mathrm{A} 2^{\prime} \mathrm{p}^{\prime} \mathrm{A}$. Nature. 1978;273:684-7.

Bisbal C, Silverman RH. Diverse functions of RNase L and implications in pathology. Biochimie. 2007;89:789-98. doi:10.1016/j.biochi.2007.02.006.

Brennan-Laun SE, Li XL, Ezelle HJ, Venkataraman T, Blackshear PJ, Wilson GM, et al. RNase L attenuates mitogen-stimulated gene expression via transcriptional and post-transcriptional mechanisms to limit the proliferative response. J Biol Chem. 2014;289:33629-43. doi:10.1074/jbc.M114.589556.
Brown GE, Lebleu B, Kawakita M, Shaila S, Sen GC, Lengyel P. Increased endonuclease activity in an extract from mouse Ehrlich ascites tumor cells which had been treated with a partially purified interferon preparation: dependence of double-stranded RNA. Biochem Biophys Res Commun. 1976;69:114-22.

Burgess HM, Mohr I. Cellular 5'-3' mRNA exonuclease Xrn1 controls double-stranded RNA accumulation and anti-viral responses. Cell Host Microbe. 2015;17:332-44. doi:10.1016/j.chom.2015.02.003.

Chakrabarti A, Ghosh PK, Banerjee S, Gaughan C, Silverman RH. RNase L triggers autophagy in response to viral infections. J Virol. 2012;86:11311-21. doi:10.1128/JVI.00270-12.

Chakrabarti A, Banerjee S, Franchi L, Loo YM, Gale Jr M, Nunez G, et al. RNase L activates the NLRP3 inflammasome during viral infections. Cell Host Microbe. 2015;17:466-77. doi:10.1016/j. chom.2015.02.010.

Dong B, Silverman RH. Alternative function of a protein kinase homology domain in $2^{\prime}, 5^{\prime}$-oligoadenylate dependent RNase L. Nucleic acids research. 1999;27:439-45. 
Drappier M, Michiels T. Inhibition of the OAS/RNase L pathway by viruses. Curr Opin Virol. 2015. doi:10.1016/j.coviro.2015.07.002.

Ezelle HJ, Malathi K, Hassel BA. The roles of RNase-L in antimicrobial immunity and the cytoskeletonassociated innate response. Int J Mol Sci. 2016;17. doi:10.3390/ijms 17010074 .

Gusho E, Baskar D, Banerjee S. New advances in our understanding of the "unique" RNase L in host pathogen interaction and immune signaling. Cytokine. 2016. doi:10.1016/j.cyto.2016.08.009.

Han Y, Whitney G, Donovan J, Korennykh A. Innate immune messenger 2-5A tethers human RNase L into active high-order complexes. Cell Rep. 2012;2:902-13. doi:10.1016/j.celrep.2012.09.004.

Han Y, Donovan J, Rath S, Whitney G, Chitrakar A, Korennykh A. Structure of human RNase L reveals the basis for regulated RNA decay in the IFN response. Science. 2014;343:1244-8. doi:10.1126/ science. 1249845 .

Hovanessian AG, Justesen J. The human $2^{\prime}-5^{\prime}$ oligoadenylate synthetase family: unique interferon-inducible enzymes catalyzing $2^{\prime}-5^{\prime}$ instead of $3^{\prime}-5^{\prime}$ phosphodiester bond formation. Biochimie. 2007;89:779-88. doi:10.1016/j.biochi.2007.02.003.

Huang H, Zeqiraj E, Dong B, Jha BK, Duffy NM, Orlicky S, et al. Dimeric structure of pseudokinase RNase $\mathrm{L}$ bound to $2-5 \mathrm{~A}$ reveals a basis for interferoninduced antiviral activity. Mol Cell. 2014;53:221-34. doi:10.1016/j.molcel.2013.12.025.

Kerr IM, Brown RE, Hovanessian AG. Nature of inhibitor of cell-free protein synthesis formed in response to interferon and double-stranded RNA. Nature. 1977;268:540-2.

Lee KP, Dey M, Neculai D, Cao C, Dever TE, Sicheri F. Structure of the dual enzyme Ire1 reveals the basis for catalysis and regulation in nonconventional RNA splicing. Cell. 2008;132:89-100. doi:10.1016/j. cell.2007.10.057.

Le Roy F, Salehzada T, Bisbal C, Dougherty JP, Peltz SW. A newly discovered function for RNase $\mathrm{L}$ in regulating translation termination. Nat Struct Mol Biol. 2005;12:505-12. doi:10.1038/nsmb944.

Le Roy F, Silhol M, Salehzada T, Bisbal C. Regulation of mitochondrial mRNA stability by RNase $\mathrm{L}$ is translation-dependent and controls IFN alpha-induced apoptosis. Cell Death Differ. 2007;14:1406-13. doi:10.1038/sj.cdd.4402130.

Liu SW, Katsafanas GC, Liu R, Wyatt LS, Moss B. Poxvirus decapping enzymes enhance virulence by preventing the accumulation of dsRNA and the induction of innate antiviral responses. Cell Host Microbe. 2015;17:320-31. doi:10.1016/j.chom.2015.02.002.

Malathi K, Dong B, Gale Jr M, Silverman RH. Small selfRNA generated by RNase L amplifies antiviral innate immunity. Nature. 2007;448:816-9. doi:10.1038/ nature 06042 .

Martinand C, Salehzada T, Silhol M, Lebleu B, Bisbal C. The RNase L inhibitor (RLI) is induced by doublestranded RNA. J Interf Cytokine Res. 1998;18:1031-8.

Siddiqui MA, Malathi K. RNase L induces autophagy via c-Jun N-terminal kinase and double-stranded RNA-dependent protein kinase signaling pathways. J Biol Chem. 2012;287:43651-64. doi:10.1074/jbc. M112.399964.

Sorgeloos F, Jha BK, Silverman RH, Michiels T. Evasion of antiviral innate immunity by Theiler's virus L* protein through direct inhibition of RNase L. PLoS Pathog. 2013;9:e1003474. doi:10.1371/journal.ppat.1003474.

Thornbrough JM, Jha BK, Yount B, Goldstein SA, Li Y, Elliott R, et al. Middle East respiratory syndrome coronavirus NS4b protein inhibits host RNase L activation. MBio. 2016;7:e0258. doi:10.1128/mBio.00258-16.

Townsend HL, Jha BK, Han JQ, Maluf NK, Silverman RH, Barton DJ. A viral RNA competitively inhibits the antiviral endoribonuclease domain of RNase L. RNA. 2008;14:1026-36. doi:10.1261/rna.958908.

Zhao L, Jha BK, Wu A, Elliott R, Ziebuhr J, Gorbalenya $\mathrm{AE}$, et al. Antagonism of the interferon-induced OAS-RNase L pathway by murine coronavirus ns2 protein is required for virus replication and liver pathology. Cell Host Microbe. 2012;11:607-16. doi:10.1016/ j.chom.2012.04.011.

Zhou A, Hassel BA, Silverman RH. Expression cloning of 2-5A-dependent RNAse: a uniquely regulated mediator of interferon action. Cell. 1993;72:753-65.

Zhou A, Paranjape J, Brown TL, Nie H, Naik S, Dong B, et al. Interferon action and apoptosis are defective in mice devoid of $2^{\prime}, 5^{\prime}$-oligoadenylate-dependent RNase L. EMBO J. 1997;16:6355-63. doi:10.1093/emboj/ 16.21.6355. 